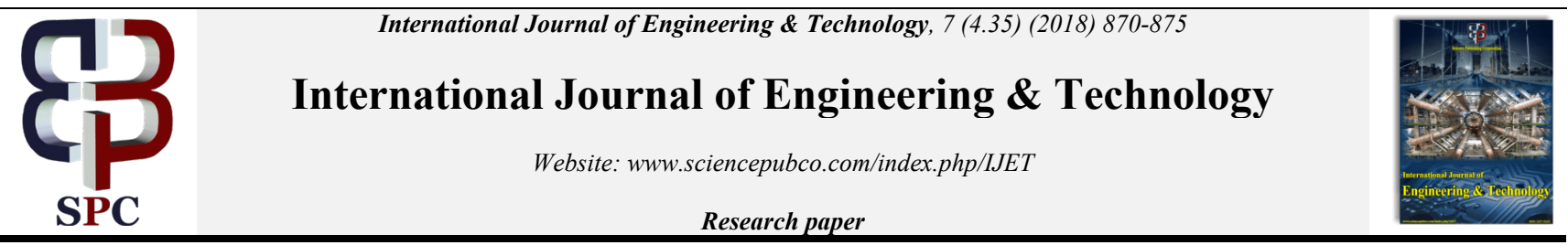

\title{
Oil Palm Empty Fruit Bunches Fiber-Supported Heterogeneous Acid Catalyst for Esterification of Oleic Acid: Effect of Different Transition Metal Sulfate
}

\author{
Shamala Gowri, Krishnan ${ }^{1}$, Fei-ling, Pua ${ }^{1,2, *}$, Kumaran Palanisamy ${ }^{1,2}$, Sharifah Nabihah Syed Jaafar ${ }^{3}$, \\ Koguleshun Subramaniam ${ }^{1}$
}

\author{
${ }^{l}$ Institute of Sustainable Energy (ISE), UNITEN, 43000 Kajang, Selangor, Malaysia \\ ${ }^{2}$ Department of Mechanical Engineering, UNITEN, 43000 Kajang, Selangor, Malaysia \\ ${ }^{3}$ Bioresources and Biorefinery Laboratory, Faculty of Science and Technology, Universiti Kebangsaan Malaysia, 43600 UKM Bangi, \\ Selangor, Malaysia \\ *Corresponding author E-mail:gracepua@uniten.edu.my
}

\begin{abstract}
This paper presents the investigation of oil palm empty fruit bunch (EFB) fiber-supported heterogeneous acid catalyst that was prepared via direct impregnation method by using various types of transition metal sulfates, including $\mathrm{Fe}_{2}\left(\mathrm{SO}_{4}\right)_{3}, \mathrm{NiSO}_{4} \cdot 6 \mathrm{H}_{2} \mathrm{O}$, and $\mathrm{CuSO}$. The EFB fiber-supported heterogeneous acid catalyst was applied for esterification of oleic acid. Hence, structural, chemical, morphological, and elemental properties of the catalyst were examined through the use of X-ray diffraction (XRD), Fourier transform infrared (FTIR), scanning electron microscope (SEM), and electron dispersive X-ray spectroscopy (EDX) analyses. Meanwhile, the acidity properties of each catalyst were characterized via acid density test. The prepared catalyst, which had been loaded with $\mathrm{Fe}_{2}\left(\mathrm{SO}_{4}\right)_{3}$, exhibited the highest acid density up to $2.4 \mathrm{mmol} / \mathrm{g}$. Next, the catalytic activity of the heterogeneous acid catalyst was further investigated through esterification of oleic acid at $60^{\circ} \mathrm{C}$ with $5 \mathrm{wt} \%$ catalyst loading for 2 hours of reaction time. The prepared catalyst, which was loaded with $\mathrm{Fe}_{2}\left(\mathrm{SO}_{4}\right)_{3}$, again displayed the high esterification conversion rate at $93.90 \%$ and was used up to five reaction cycles.
\end{abstract}

Keywords: Heterogeneous Catalyst; Oil Palm Empty Fruit Bunch; Esterification; Oleic Acid

\section{Introduction}

The increase in demand and supply for world energy production has led to rather serious environmental issues due to high dependency and usage of fossil fuels. Hence, the depletion of fossil energy supply has driven towards innovation of new fuel. Since the existing supply can only cater to the escalating demands until the year 2023, an alternative source is direly sought [1]. Hence, in order to overcome this particular alarming issue, biodiesel has been initiated as a new source of energy, which can serve as substitute petroleum, mainly in the transportation sector. Biodiesel known as fatty acid methyl ester (FAME) that is consisted of alkyl esters of fatty acids produced from vegetable oil. Biodiesel is also renewable, biodegradable, less pollutant, non-toxic, and environmentally beneficial, in comparison to fossil fuel. Based on the Renewable Energy Policy Network report published in 2014, biodiesel appeared to have the highest demand in the last decades with 15 times growth in production from 2002 until 2012, hence signifying increment in its consumption [2]. In fact, the demand for biodiesel has also been active in Asia apart from the United States and European countries. Therefore, the Malaysian government extensively studies the conversion of crude fossil fuel to biofuel production and its consumption [3]. In fact, they also has begun initiating these biodiesel projects involving palm oil since 1982. Such initiation resulted in the implementation of The Na- tional Biofuel Policy established in 2006. The initial program of B5 in 2013 that uses palm oil as a feedstock was implemented, whereby B5 consists of $5 \%$ palm methyl ester blend with $95 \%$ petroleum diesel [4]. The primary reason for the production of biodiesel is to lower exhaust emission, as well as to produce a sulfur and carcinogenic free fuel [5]. Since then, biodiesel production continued with the implementation of B7 in 2015 and B10 which is yet to be introduced. The most common method used is the transesterification of triglycerides. The reaction is generated by using short-chain alcohols, commonly methanol and homogeneous alkaline catalyst. An alkali catalyzed reaction can achieve higher yield but the drawback is its sensitivity towards the type of feedstock used in the reaction. Refined vegetable oils have a low amount of free fatty acid (FFA) can be used as feedstock in the reaction. Furthermore, the major drawback is the raw materials used for biodiesel production may cost more than $70-75 \%$ of the total biodiesel cost. Thus, feedstock cost can be reduced by using unrefined and non-edible oil, animal fats, and waste cooking oils. However, the presence of FFA in those feedstock appears to be a problem in biodiesel production. Feedstock with high FFA content reacts with alkaline catalyst during transesterification reaction and cause soap formation which reduces the product yield. Therefore, feedstock with high FFA can be treated via esterification reaction by using acid catalyst prior to transesterification reaction. Conventionally, homogeneous catalysts such as sulfuric acid and sodium hydroxide have been extensively used in biodiesel production [6]. 
Unfortunately, these homogeneous catalysts have contributed to the major drawbacks due to poor catalyst separation, harmful chemical secretion into the environment and lead to reactor corrosion [7]. Thus, to address the existing problems, various studies have conducted in preparing heterogeneous catalyst that could ease catalyst recovery and recyclability [8]. There are various types of heterogeneous acid catalysts including ion-exchange resins, transition metal, metal oxides, zeolites, and sulfated acid, which have the potential for sustainable biodiesel production [9]. However, there are certain disadvantages of these catalysts such as non-biodegradable, high production cost, and poor recyclability due to catalyst deactivation in the presence of water [10]. Furthermore, poor porosity appears to be a major issue among these catalysts, which inhibit accessibility of reactants to active sites via catalysis reaction [11]. Besides, good heterogeneous acid catalysts are generally classified based on acidic strength, the morphology of the support's surface area, and porosity. A few studies have applied the heterogeneous acid catalyst to direct transesterification. In this context, carbon supported heterogeneous acid catalysts able to provide efficient performance in esterification of FFA. In addition, these materials are relatively cheap, readily available and can be functionalized directly with sulfonic group $(-\mathrm{SO} 3 \mathrm{H})$ via sulfonation or acid treatment [12]. Sulfonation of carbon materials generates solidity with high stability and exhibit high acid density (-SO3H) [13]. A number of studies have applied carbon-based material for heterogeneous catalyst production. Sulfated catalysts have an advantage of high acid density which results in good catalytic performance. Liu et al., [14] findings showed that the acid density of the prepared catalyst was $2.64 \mathrm{mmol} / \mathrm{g}$ which suggests the formation of a large fraction of acid site on the surface of the catalyst. The catalyst was then carbonized at $300 \mathrm{oC}$ for $1 \mathrm{~h}$ and it was used to catalyze the esterification of oleic acid. As a result, it recorded the highest conversion yield of $98 \%$ compared to a commercial catalyst with $84 \%$. Malaysia being the second largest produtcion of palm oil in the world while in 2016, it was recorded that approximately 17.3 million metric tons of palm oil being produced [15]. Due to the escalating production growth and activities in the oil palm industry, inappropriate handling of biomasses can cause severe environmental issues. Statistically, EFB appears to be one of the most abundant waste biomasses with around 12.4 million tons being generated at an annual basis [16]. EFB is a fibrous biomass that has been used as a source of heat and power for incineration to generate steam in palm oil mills. To date, studies on EFB fiber supported heterogeneous acid catalyst have yet to be reported. Transition metals classified as d block metals that forms stable ions with incompletely filled d-orbitals. The surface of transition metal provides an absorption capacity to the support material thus considered to be an ideal catalyst for the catalytic reaction. However, studies concerning on the use of transition metal sulfates still ongoing and to address the issue, studies can be focused to investigate their catalytic activity. Instead of using concentrated sulfuric acid, transition metal sulfates can be used to prepare heterogeneous acid catalysts. For example, Okić et al., [17] examined iron sulfate derived silica $(\mathrm{Fe} 2(\mathrm{SO} 4) 3 / \mathrm{SiO} 2)$ prepared via titration method by using porous silica with $30 \mathrm{wt} \%$ of iron sulfate solution. It reported with the highest conversion of $96.9 \%$. The primary aim of this particular study is to prepare and to characterize EFB fibersupported heterogeneous acid catalysts, as well as to evaluate the catalytic activity by the esterification reaction. New catalysts were generated from oil palm waste with enhanced properties by using the one-step preparation method. In the present work, the EFB fiber-supported heterogeneous solid catalysts were prepared via direct impregnation using various types of transition metal sulfates. The series of catalysts had been further calcined at $500 \mathrm{oC}$. In addition, the characteristics of the catalyst were evaluated by employing different types of analyses. Furthermore, the catalytic activities of the prepared catalysts were determined via esterification of oleic acid with methanol. On top of that, the recyclability of catalysts and a comparison with a commercial catalyst were also investigated.

\section{Experimental}

\subsection{Materials}

Shredded oil palm EFB fiber was obtained from Sztech Engineering Sdn Bhd (Shah Alam, Selangor, Malaysia). Meanwhile, Iron (III) Sulfate $\left(\mathrm{Fe}_{3}\left(\mathrm{SO}_{4}\right)_{2}\right)$, Copper Sulfate Hydrate $\left(\mathrm{CuSO}_{4}\right)$, and Nickel Sulfate Hexahydrate $\left(\mathrm{NiSO}_{4} \cdot 6 \mathrm{H}_{2} \mathrm{O}\right)$ powders that were used to prepare the catalyst had been purchased from Suria Pembekal Umum Sdn Bhd (Malaysia) and had analytical grade. Next, industrial oleic acid (196 mg KOH/g) (R\&M, Malaysia) and methanol were used as materials for the esterification reaction.

\subsection{Catalyst Preparation}

In preparing the catalyst, pre-treated EFB fibers were sieved to the size range of $125-150 \mu \mathrm{m}$. The heterogeneous acid catalyst was prepared with three different types of transition metal sulfates, which were: $\mathrm{Fe}_{3}\left(\mathrm{SO}_{4}\right)_{2}, \mathrm{CuSO}_{4}$, and $\mathrm{NiSO}_{4} \cdot 6 \mathrm{H}_{2} \mathrm{O}$, via direct impregnation method. The method was performed at $60{ }^{\circ} \mathrm{C}$ with continuous stirring for 2 hours. The prepared samples were then ovendried at $105^{\circ} \mathrm{C}$ for $24 \mathrm{~h}$ to remove excess water. The dried sample was powdered well and calcined at $500{ }^{\circ} \mathrm{C}$ for 3 hours. Next, a series of heterogeneous catalysts had been prepared by using different transition metal sulfates. These catalysts were kept at $50{ }^{\circ} \mathrm{C}$ prior to catalyst characterization. The catalysts were denoted as $\mathrm{Fe}_{3}\left(\mathrm{SO}_{4}\right)_{2}(\mathrm{FS}), \mathrm{CuSO}_{4}(\mathrm{CS})$, and $\mathrm{NiSO}_{4} \cdot 6 \mathrm{H}_{2} \mathrm{O}(\mathrm{NS})$

\subsection{Catalyst Characterization}

Scanning electron microscopy (SEM) equipped with electron dispersive X-ray spectroscopy (EDX) conducted on JSM6010PLUS/LV equipment, Japan was employed to examine the surface morphology and the elemental composition that appeared on the surface of the catalysts. X-ray diffraction (XRD) analysis was carried out with 6000 Shimadzu, Japan. The XRD patterns were measured with the following conditions: $\mathrm{Cu} K \alpha$ radiation $(\lambda$ $=0.154 \mathrm{~nm}$ ), tube voltage of $30 \mathrm{Kv}$, tube current of $20 \mathrm{~mA}$, scanning speed of $3 \mathrm{o} / \mathrm{min}$, and scanning range of $10-90 \mathrm{o}$. Solid samples were used in this analysis in order to determine the structure of crystalline materials. Next, Fourier transform infrared (FTIR) spectroscopy analysis was carried out on Perkin Elmer FTIR-BX, whereby the FTIR spectra were recorded in the range of 4000-400 $\mathrm{cm}-1$. The ester group of esterified samples was identified by detecting the presence of functional groups in the samples. After that the acid density of this was estimated by using the acid-base titration method. Hence, $0.5 \mathrm{~g}$ of dried catalyst with $50 \mathrm{ml}$ of $0.1 \mathrm{M}$ $\mathrm{NaCl}$ solution was stirred continuously for $30 \mathrm{~min}$. Then, the filtrate was collected and titrated via $0.1 \mathrm{M} \mathrm{NaOH}$ solution added with phenolphthalein as the indicator. Lastly, the free $\mathrm{H}+$ present in the filtrate was evaluated via titration with $\mathrm{NaOH}$ solution. 


\subsection{Esterification Reaction}

The esterification reactions were carried out in a three-neck flat bottom flask equipped with reflux condenser. A mixture of $30 \mathrm{~g}$ oleic acid, methanol to oil molar ratio of $10: 1$, and $5 \%$ catalyst loading were continuously stirred at $60{ }^{\circ} \mathrm{C}$ for $2 \mathrm{~h}$ and later, agitated at $350 \mathrm{rpm}$. After the reaction, the heterogeneous acid catalysts were recovered via vacuum filtration. The water and excess methanol were removed from the esterified product through evaporation. Finally, the used heterogeneous acid catalysts were washed and oven-dried for recyclability study was carried out.

\subsubsection{Comparison with Commercial Catalyst}

The performance of the best conversion exerted by heterogeneous acid catalyst was compared with a polymer resin called Amberlyst DB-20 via esterification reaction. After the reaction, the heterogeneous acid catalysts were recovered via vacuum filtration.

\subsection{Product Characterization}

Conversion of FFA was evaluated by using the potassium hydroxide $(\mathrm{KOH})$ titration method. The acid value of esterified sample from oleic acid was tested by employing the ASTM D664 method. The acid value (Eq. 1) and the FFA conversion (Eq. 2) were calculated by using the equations depicted in the following:

$$
\text { Acid value }(\mathrm{mg} \mathrm{KOH} / \mathrm{g})=\mathrm{V}_{\mathrm{KOH}} \times 56.1 \times \mathrm{C}_{\mathrm{KOH}}
$$

where $\mathrm{V}_{\mathrm{KOH}}(\mathrm{ml})$ is consumed volume of standard $\mathrm{KOH}, 56.1$ gmol $^{-1}, \mathrm{C}_{\mathrm{KOH}}$ refers to concentration of standard $\mathrm{KOH}$, and $\mathrm{m}_{\text {sample }}$ (g) denotes weight of the sample used in every titration.

Esterification conversion $(\%)=\mathrm{AV}_{\mathrm{O}}-\mathrm{AV}_{\mathrm{N}} \times 100 \%$

$$
\mathrm{AV}_{\mathrm{O}}
$$

where $\mathrm{AV}_{\mathrm{O}}\left(\mathrm{mg} \mathrm{KOH} \mathrm{g}^{-1}\right)$ is initial acid value of oleic acid, and $\mathrm{AV}_{\mathrm{N}}\left(\mathrm{mg} \mathrm{KOH} \mathrm{g}{ }^{-1}\right)$ denotes acid value of esterified samples.

\section{Results and Discussion}

\subsection{Catalyst Characterization}

\subsubsection{Morphology Analysis}

The surface morphology analysis of heterogeneous acid catalyst had been determined via SEM analysis. The morphology of heterogeneous acid catalyst prepared with varying transition metal sulfates, including $\mathrm{Fe}_{2}\left(\mathrm{SO}_{4}\right)_{3}, \mathrm{CuSO}_{4}$, and $\mathrm{NiSO}_{4} \cdot 6 \mathrm{H}_{2} \mathrm{O}$, is as illustrated in Fig. 1. As shown in Fig. 1a, the particles are successfully dispersed on the fiber surface. The particles are spherical in shape and one can observe that they are aggregated on the surface of the EFB at higher temperature. In addition, the copper particles display the formation of small spherical particles of $\mathrm{CuSO}_{4}$ coated on EFB surface (Fig. 1b). Besides, the nickel particles are comprised of spongy layer with tiny openings on the EFB surface (Fig. 1c) Hence, the dissemination of particles on the surface of EFB fiber varies with the varied transition metal sulfates at $500{ }^{\circ} \mathrm{C}$ calcination temperature.
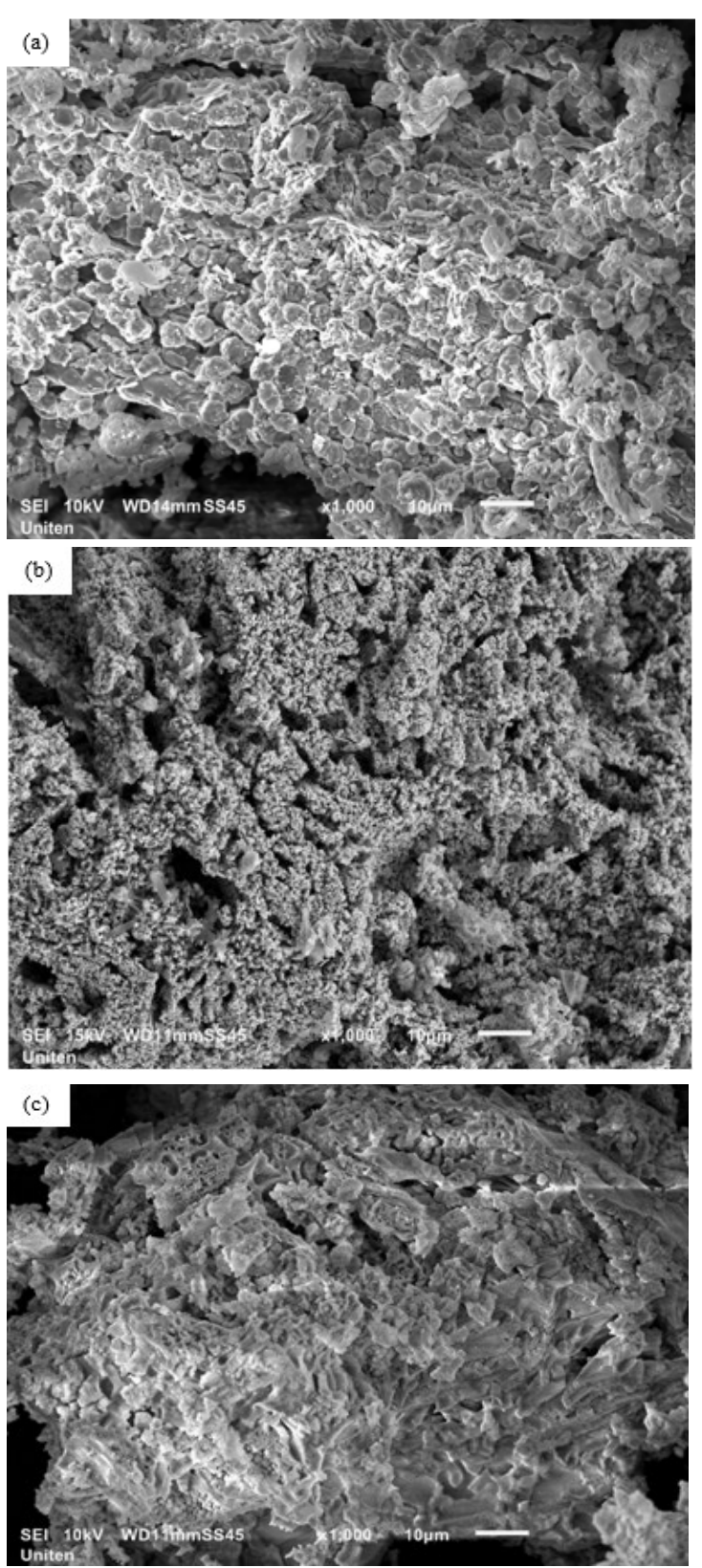

Fig. 1: SEM images of (a) FS catalyst calcined at $500^{\circ} \mathrm{C}$, (b) CS catalyst calcined at $500^{\circ} \mathrm{C}$ and NS catalyst calcined at $500^{\circ} \mathrm{C}$

\subsubsection{EDX Analysis}

The EDX results reflect the composition of chemical elements on the surface of catalysts. The findings tabulated in Table 1 present the composition of oxygen, sulfur, and transition metal elements for varied catalysts. The FS heterogeneous acid catalyst calcined at $500{ }^{\circ} \mathrm{C}$ reported the highest sulfur (S) content at $17.70 \mathrm{wt} \%$, in comparison to that of CS and NS catalysts at $2.53 \%$ and $17.24 \%$, respectively. The EDX analysis also displayed a significant number of transition metals $(\mathrm{Fe}, \mathrm{Cu}$, and $\mathrm{Ni}$ ) and oxygen $(\mathrm{O})$ in respective catalysts, where the amount of $\mathrm{Fe}$ and $\mathrm{O}$ of FS catalyst suggests the existence of iron oxide $\left(\mathrm{Fe}_{2} \mathrm{O}_{3}\right)$ on the support materials. The findings of EDX analysis is consistent with that obtained from the SEM analysis, where FS-500 ${ }^{\circ} \mathrm{C}$ catalyst was successfully impregnated with ferric and sulfur elements on the fiber surface.

Table 1: Elemental analysis of various heterogeneous acid catalyst calcined at $500^{\circ} \mathrm{C}$

\begin{tabular}{|c|c|c|c|}
\hline Catalysts & $\begin{array}{c}\text { Oxygen (O) } \\
(\mathrm{wt} \%)\end{array}$ & $\begin{array}{c}\text { Sulfur }(\mathrm{S}) \\
(\mathrm{wt} \%)\end{array}$ & $\begin{array}{c}\text { Transition metal } \\
(\mathrm{Fe}, \mathrm{Cu}, \mathrm{Ni})(\mathrm{wt} \%)\end{array}$ \\
\hline $\mathrm{FS}$ & 49.00 & 17.70 & 33.30 \\
\hline $\mathrm{CS}$ & 22.63 & 2.53 & 74.83 \\
\hline
\end{tabular}




\begin{tabular}{l|l|l|l} 
NS & 38.00 & 17.24 & 44.77 \\
\hline
\end{tabular}

\subsubsection{FTIR Analysis}

The FTIR spectroscopy was employed to examine the presence of functional groups in the catalysts. The FTIR spectra for heterogeneous acid catalyst calcined at $500{ }^{\circ} \mathrm{C}$ are portrayed in Fig. 2. The characteristic bands at $597,476,454$, and $446 \mathrm{~cm}^{-1}$ indicate the formation of hematite upon the increasing calcination temperature, which is attributed to Fe-O bending vibration (Fig. 2a) [18]. Besides, the significant peaks noted in acid heterogeneous catalyst samples at 515.04 and $525.30 \mathrm{~cm}^{-1}$ for NS (Fig. 2b) and FS, respectively, signify the presence of disulfide (S-S) group in the catalyst. Besides, no trace of sulfur group is noted in CS (Fig. 2c). However, the frequency at $1098 \mathrm{~cm}^{-1}$ points out the presence of thiocarbonyl of $\mathrm{C}=\mathrm{S}$, which corresponds to the lower sulfur content in EDX analysis. The intensity of peaks proves the existence of sulfonic groups, while FS appears to be a potential catalyst, where the finding is consistent with both acid density and EDX results.
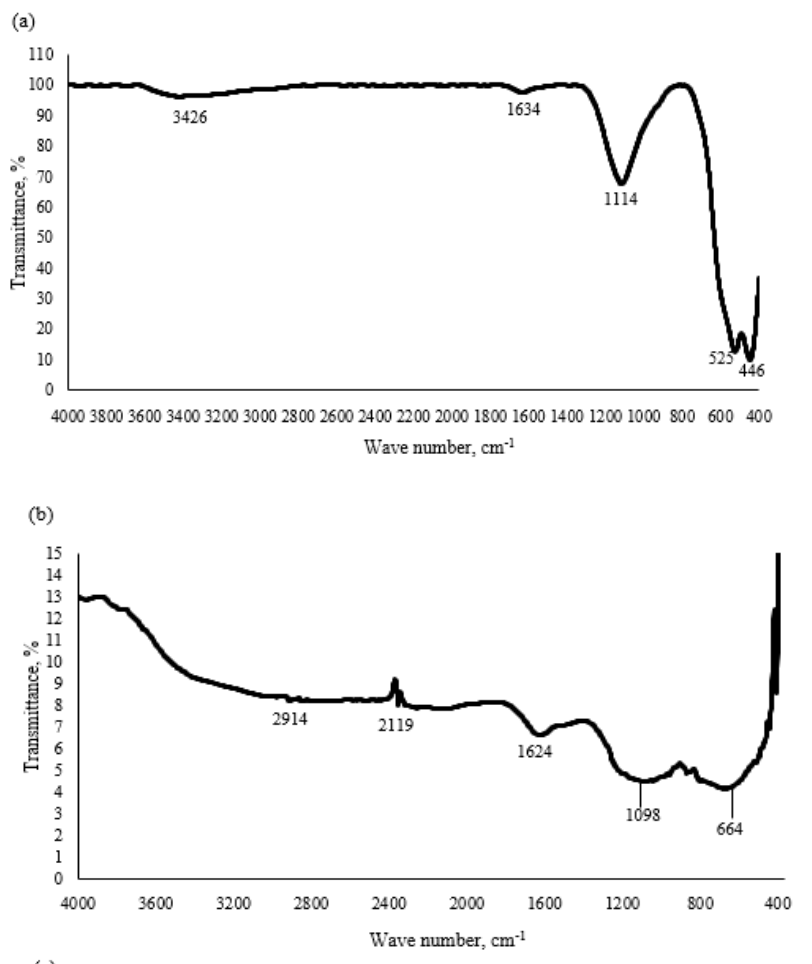

(c)

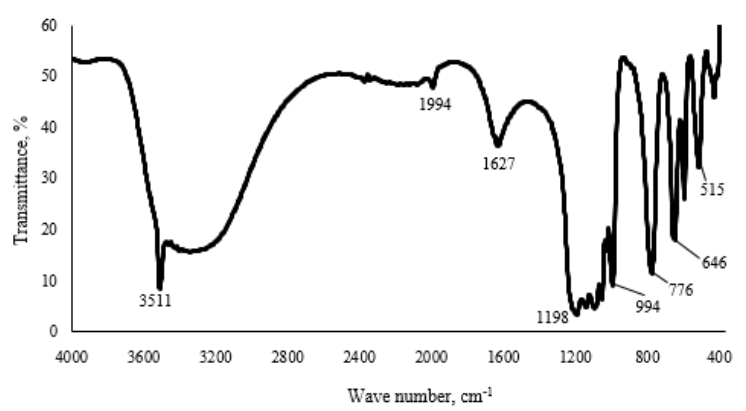

Fig. 2: FTIR spectra of (a) FS, (b) CS and (c) NS

\subsubsection{XRD Analysis}

The XRD patterns of heterogeneous acid catalysts are illustrated in Fig. 3. Based on the XRD profile, slight sharp characteristic diffraction peaks with $2 \theta$ at $33.2^{\circ}, 35.7^{\circ}$, and $54.1^{\circ}$ (JCPDS file No: 00-033-0664) resemble rhombohedral structure. The XRD patterns indicate that iron oxide is in the form of hematite, $\alpha-\mathrm{Fe}_{2} \mathrm{O}_{3}$, which correlates with IR spectra of this compound. The average structural size of the catalyst, hence, could be estimated to be 7.32 $\mathrm{nm}$ at $500{ }^{\circ} \mathrm{C}$. Meanwhile, a strong crystalline peak for CS is observed around $2 \theta$ at $25.0^{\circ}, 34.2^{\circ}$, and $21.2^{\circ}$ (JCPDS file No: 00 015-0775), which can be attributed to (111), (211), and (011) planes, respectively indicating orthorhombic structure, while the average structural size of catalyst may be $7.90 \mathrm{~nm}$. The XRD peaks are characterized as (200), (111), and (220) planes at $43.3^{\circ}$, $37.2^{\circ}$, and $62.8^{\circ}$, respectively (JCPDS file No: 00-047-1049). This signifies the formation of cubic structure for nickel oxide and the fact that the average structural size of the particles is $5.29 \mathrm{~nm}$. Furthermore, one can note that NS has smaller particle sizes when compared to FS and CS. Nevertheless, a good catalytic activity can be reflected from the high amount of acid sites in the catalyst and hence, FS appear to be a potential catalyst for esterification reaction.

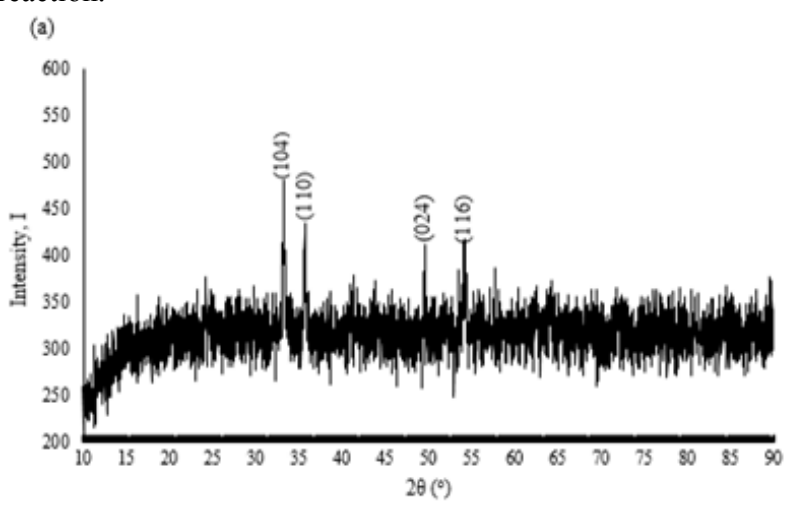

(b)

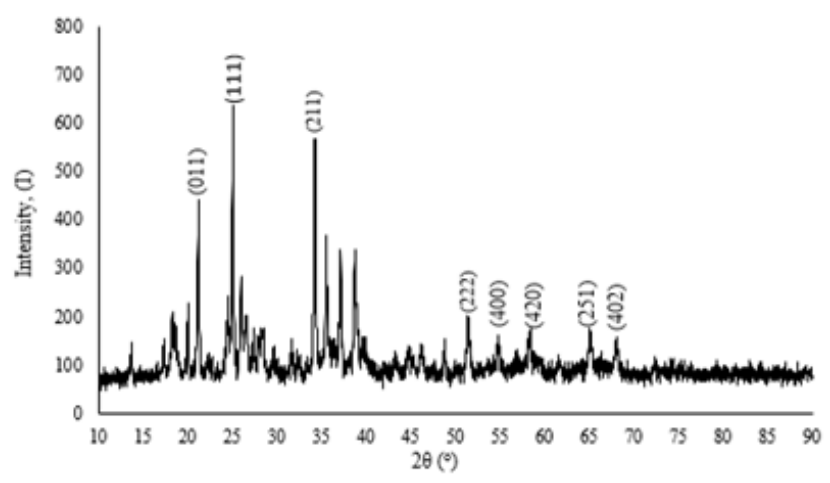

(c)

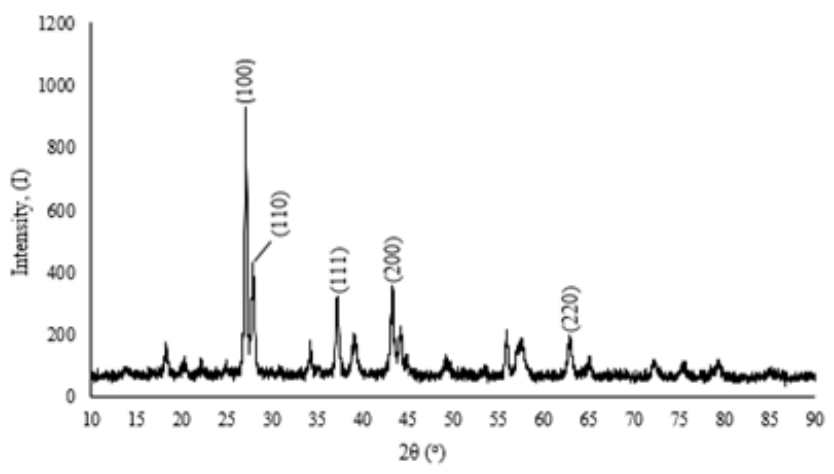

Fig. 3: XRD pattern of (a) FS, (b) CS and (c) NS

\subsubsection{Acid Density Analysis}

The acid strength of EFB fiber supported with varied types of heterogeneous acid catalysts calcined at $500^{\circ} \mathrm{C}$ had been examined with $\mathrm{NaOH}$ titration. As a result, FS achieved the highest acidity of $2.4 \mathrm{mmol} / \mathrm{g}$, when compared to other catalysts. The high acid density value contributes to the presence of $-\mathrm{SO}_{3} \mathrm{H}$ (sulfonic acid) group in the catalyst, which may probably be an active site for esterification reaction. The acid density of NS was recorded to be 
the lowest at $0.2 \mathrm{mmol} / \mathrm{g}$ due to the structural characteristic, which may lead to weak ion exchange between sulphur and sodium ions. Next, CS resulted in $1.7 \mathrm{mmol} / \mathrm{g}$, primarily due to the attachment of sulphur groups in the catalyst. Therefore, FS exhibited high acid density result in comparison to other catalysts.

\subsection{Esterification Reaction}

\subsubsection{Effect of Different Types of Transition Metal Sulfate Catalysts}

The efficiency of heterogeneous acid catalyst had been investigated via esterification reaction on oleic acid. The highest conversion of oleic acid was observed at $93.9 \%$ by using FS catalyst calcined at $500^{\circ} \mathrm{C}$. Meanwhile, CS and NS catalysts calcined at $500^{\circ} \mathrm{C}$ displayed conversion values of $61.86 \%$ and $71.84 \%$, respectively. Hence, the existence of sulfonic acid groups on the surface of FS catalyst portrays higher conversion rate, when compared to that in other heterogeneous acid catalysts. Therefore, this explains that catalyst calcined at $500^{\circ} \mathrm{C}$ contributes to the dispersion of particle structure on the surface of EFB fiber, thus easing the interaction between oleic acid and active site, especially during esterification reaction [19].

\subsubsection{Ester Group from FTIR Analysis}

The determination of ester groups in the esterified product had been carried out by using FTIR analysis. The FTIR spectra of esterified methyl oleate reflect three different transition metal sulfates based on heterogeneous acid catalysts, as depicted in Fig. 4. The frequencies at $2922.85,2858.60,2921.00$, and $2853.00 \mathrm{~cm}$ ${ }^{1}$ correspond to the $\mathrm{C}-\mathrm{H}$ stretching bonds that signify the existence of hydrocarbon. On the other hand, frequencies 1733.68 and $1708.00 \mathrm{~cm}^{-1}$ are attributable to the $\mathrm{C}=\mathrm{O}$ stretching bond, hence indicating the presence of carbonyl group in the esterified products [20]. Meanwhile, frequencies 1178.91, 1013.43, 1282.00, 931.00 , and $932.00 \mathrm{~cm}^{-1}$, which are assigned to the C-O stretching bonds points out the presence of three elements, which are alcohol, ester, and carboxylic acid. Thus, the results that indicate the presence of ester groups prove that oleic acid has successfully esterified methyl oleate by using FS, CS, and NS.

(a)

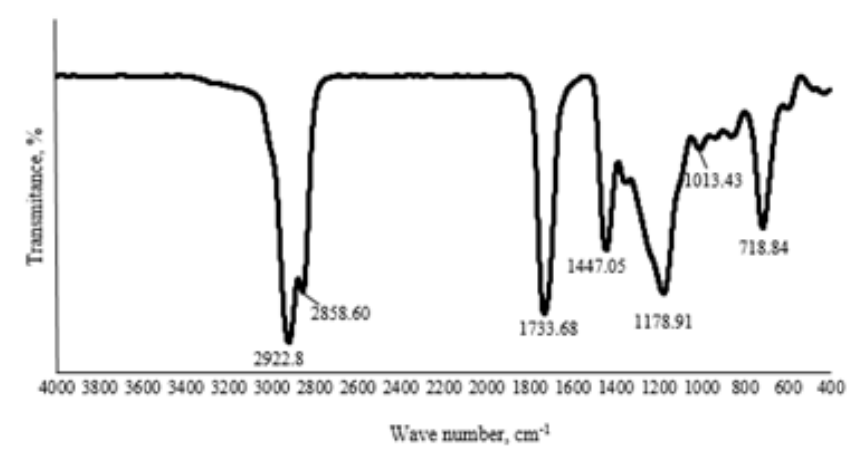

(b)

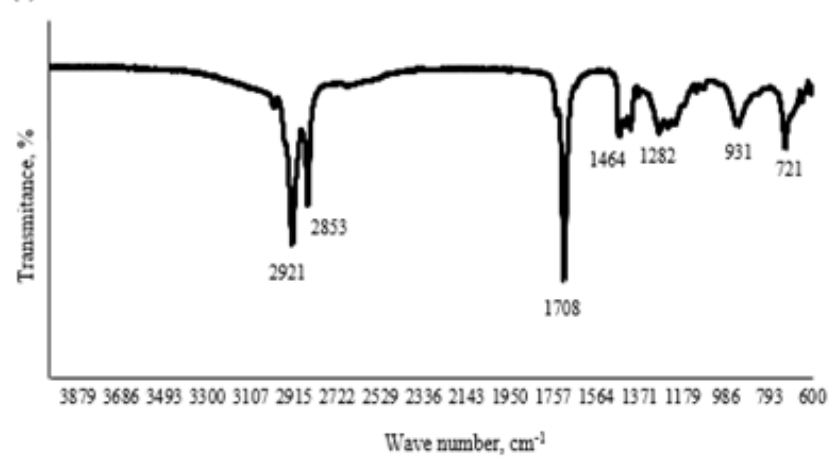

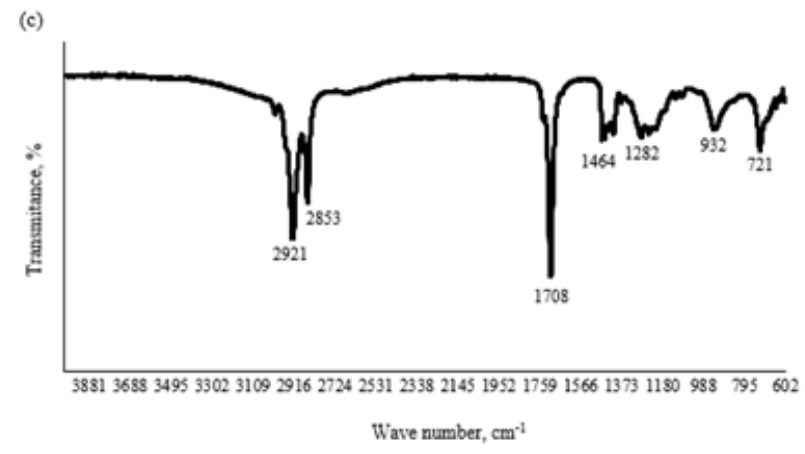

Fig. 4: FTIR spectra of esterified methyl oleate (a) FS, (b) CS and (c) NS

\subsubsection{Comparison with Commercial Catalyst}

The comparison between Fe-SAC and commercial polymer resin, Amberlyst DB-20, had been evaluated under similar esterification parameters for both catalysts. The highest esterification conversion was $93.90 \%$ obtained by FS calcined at $500{ }^{\circ} \mathrm{C}$, while $\mathrm{Am}-$ berlyst BD-20 recorded slightly lower FFA conversion at $83.40 \%$. Besides, biomass supported by catalyst exerted enhanced performance in comparison to the commercial catalyst. The lower yield of commercial catalyst is likely due to the water present in the reaction that blocks the active sites of the catalyst.

\subsection{Catalyst Recyclability}

The study of recyclability for the heterogeneous catalysts had been looked into in order to determine the performance of the prepared catalysts at optimum reaction conditions via esterification reaction. After each run, the catalyst was washed with n-butanol and dried at $60{ }^{\circ} \mathrm{C}$ before use. Fig. 5 illustrates the catalytic activity of the heterogeneous acid catalysts of FS, CS, and NS. As resulted, the catalyst activity gradually decreased with the minimum loss of activity for FS after five cycles of reaction. Moreover, FS displayed a stable activity with its initial activity at $93.90 \%$ and $80.19 \%$ after five cycles. On the other hand, a drastic decrease had been observed for CS from 62.46 to $46.32 \%$, whereas 71.84 to $62.81 \%$ for NS. Furthermore, it was observed that the reduction in FFA conversion might due to the leaching of $-\mathrm{SO}_{3} \mathrm{H}$ groups from the catalyst. This study has proven that FS exhibits high catalytic activity after 5 cycles, which can be attributed to the presence of active site on the surface of the catalyst after each cycle.

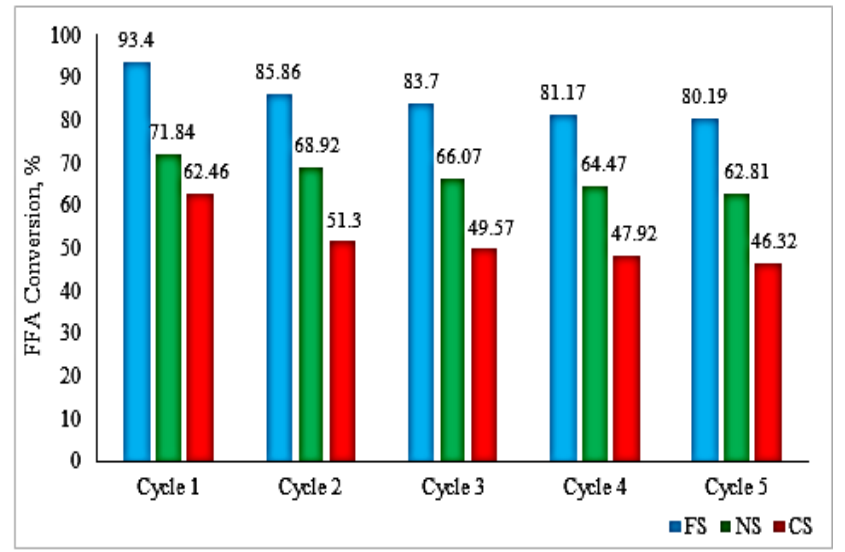

Fig.5: Profile of FFA conversion (\%) on esterification of oleic acid for 5 cycles

\section{Conclusion}

In this study, EFB fiber-supported heterogeneous acid catalysts had been successfully generated via direct impregnation by using transition metal sulfates, which are: $\mathrm{Fe}_{2}\left(\mathrm{SO}_{4}\right)_{3}, \mathrm{CuSO}_{4}$, and $\mathrm{Ni}$ $\mathrm{SO}_{4} \cdot 6 \mathrm{H}_{2} \mathrm{O}$ calcined at $500{ }^{\circ} \mathrm{C}$, while their performances were 
evaluated via esterification of oleic acid. A conversion of $93.90 \%$ had been achieved by using FS catalyst with a high acid density of $2.4 \mathrm{mmol} / \mathrm{g}$, in comparison to that of CS and NS catalysts. In addition, when compared with the commercial polymer resin, Amberlyst BD-20, EFB fiber-supported $\mathrm{Fe}_{2}\left(\mathrm{SO}_{4}\right)_{3}$ catalyst exhibited higher catalytic activity. Meanwhile, the FS catalyst was further reused and $80.19 \%$ was retrieved after five cycles. This finding shows that biomass supported with heterogeneous catalyst appears to be a potential as an environmental-friendly catalyst and most importantly, cost-effective.

\section{Acknowledgment}

The authors wish to acknowledge the financial support from Ministry of Higher Education (MOHE) Fundamental Research Grant Scheme (20140118FRGS) and UNITEN BOLD Grant (10289176/B/9/2017/21).

\section{References}

[1] N. Muda and T. Jin Pin, "On Prediction of Depreciation Time of Fossil Fuel in Malaysia," J. Math. Stat., vol. 8, no. 1, pp. 136-143, 2012.

[2] S. K. Loh, "The potential of the Malaysian oil palm biomass as a renewable energy source," Energy Convers. Manag., vol. 141, pp. 285-298, 2017.

[3] M. H. M. Yusoff, A. Z. Abdullah, S. Sultana, and M. Ahmad, "Prospects and current status of B5 biodiesel implementation in Malaysia," Energy Policy, vol. 62, pp. 456-462, 2013.

[4] N. Boz, N. Degirmenbasi, and D. M. Kalyon, "Esterification and transesterification of waste cooking oil over Amberlyst 15 and modified Amberlyst 15 catalysts," Appl. Catal. B Environ., vol. 165, pp. 723-730, 2015.

[5] Z. Gao, S. Tang, X. Cui, S. Tian, and M. Zhang, "Efficient mesoporous carbon-based solid catalyst for the esterification of oleic acid," Fuel, vol. 140, pp. 669-676, 2015.

[6] P. Jaggernauth-Ali, E. John, and P. Bridgemohan, "The application of calcined marlstones as a catalyst in biodiesel production from high free fatty acid coconut oil," Fuel, vol. 158, pp. 372-378, 2015.

[7] N. Mansir, Y. H. Taufiq-Yap, U. Rashid, and I. M. Lokman, "Investigation of heterogeneous solid acid catalyst performance on low-grade feedstocks for biodiesel production: A review," Energy Convers. Manag., 2016.

[8] M. A. Tejero, E. Ramírez, C. Fité, J. Tejero, and F. Cunill, "Esterification of levulinic acid with butanol over ion exchange resins," Appl. Catal. A Gen., vol. 517, pp. 56-66, 2016.

[9] S. Soltani, U. Rashid, S. I. Al-Resayes, and I. A. Nehdi, "Recent progress in synthesis and surface functionalization of mesoporous acidic heterogeneous catalysts for esterification of free fatty acid feedstocks: A review," Energy Convers. Manag., 2016.

[10] G. C. Chen et al., "Efficient synthesis of biodiesel over welldispersed sulfated mesoporous $\mathrm{SiO} 2$ colloidal spheres," Fuel Process. Technol., vol. 134, pp. 11-17, 2015.

[11] M. Zhang, A. Sun, Y. Meng, L. Wang, H. Jiang, and G. Li, "High activity ordered mesoporous carbon-based solid acid catalyst for the esterification of free fatty acids," Microporous Mesoporous Mater. vol. 204, no. C, pp. 210-217, 2015.

[12] T. Liu, Z. Li, W. Li, C. Shi, and Y. Wang, "Preparation and characterization of biomass carbon-based solid acid catalyst for the esterification of oleic acid with methanol," Bioresour. Technol., vol. 133, pp. 618-621, 2013.

[13] Q. Shu, H. Yuan, B. Liu, L. Zhu, C. Zhang, and J. Wang, "Synthesis of biodiesel from model acidic oil catalyzed by a novel solid acid catalyst SO42-/C/Ce4+," Fuel, vol. 143, pp. 547-554, 2015.

[14] S. H. Chang, "An overview of empty fruit bunch from oil palm as feedstock for bio-oil production," Biomass and Bioenergy, vol. 62, pp. 174-181, 2014

[15] H. B. Aditiya, W. T. Chong, T. M. I. Mahlia, A. H. Sebayang, M. A. Berawi, and H. Nur, "Second generation bioethanol potential from selected Malaysia's biodiversity biomasses: A review," Waste Manag., vol. 47, pp. 46-61, 2016.

[16] M. F. Awalludin, O. Sulaiman, R. Hashim, and W. N. A. W. Nadhari, "An overview of the oil palm industry in Malaysia and its waste utilization through thermochemical conversion, specifically via liquefaction," Renew. Sustain. Energy Rev., vol. 50, pp. 1469$1484,2015$.

[17] M. Okić, Ž. Kesić, J. Krstić, D. Jovanović, and D. Skala, "Decrease of free fatty acid content in vegetable oil using silica supported ferric sulfate catalyst," Fuel, vol. 97, pp. 595-602, 2012.

[18] L. Wang, X. Dong, H. Jiang, G. Li, and M. Zhang, "Ordered mesoporous carbon supported ferric sulfate: A novel catalyst for the esterification of free fatty acids in waste cooking oil," Fuel Process. Technol., vol. 128, pp. 10-16, 2014.

[19] X. Y. Liu et al., "Preparation of a carbon-based solid acid catalyst by sulfonating activated carbon in a chemical reduction process," Molecules, vol. 15, no. 10, pp. 7188-7196, 2010.

[20] A. Hykkerud and J. M. Marchetti, "Esterification of oleic acid with ethanol in the presence of Amberlyst 15," Biomass and Bioenergy, vol. 95, pp. 340-343, 2016. 